\title{
O uso da sonoridade nas Odes Píticas de Píndaro
}

\author{
C. Leonardo B. Antunes \\ Universidade de São Paulo \\ leo.antunes@uol.com.br
}

\begin{abstract}
In this article, we will attempt to analyse certain aspects of Pindar's style through the study of a few figures of speech that were used by the poet in the Pythian Odes. We will also strive to understand the way by which those structural elements, mostly tied to sound, interact with the remaining aspects and content of those poems. During that analysis, it will become clear that, when studying a poet of great genius such as Pindar, one must read the text and see it through its own rules and, conversely, not by those commonly applied to similar types of poetry.
\end{abstract}

KEYWORDS: Greek; lyric; Pindar; stylistic.

Neste artigo, procuraremos analisar alguns aspectos do estilo de Píndaro tal ele se apresenta nas Odes Píticas. O foco de nosso interesse, aqui, reside no campo sonoro e na maneira pela qual os elementos deste âmbito se relacionam com os demais aspectos dos poemas em que se encontram. Durante esta análise, em que se buscará verificar de que maneira a forma dialoga com o conteúdo das passagens estudadas, observaremos uma certa dificuldade ou ineficácia em enquadrar, tal qual rege a gramática, as figuras de construção utilizadas por um poeta exemplar como Píndaro, forçando-nos a abandonar uma visão tradicional e apreender o texto por meio de suas próprias regras.

O interesse e o modus operandi apresentados neste estudo não são de todo novos, mas, sim, alinham-se com o método de trabalho proposto por Race em Style and Rhetoric in Pindar's Odes. ${ }^{1}$ Em seu livro, ao criticar o caminho pelo qual os estudos estilísticos costumavam trilhar até então, o autor propõe que se estude o estilo de um determinado poema não como um fenômeno isolado, mas como aspecto inerente à própria lógica do texto, procurando avaliar sua função e seu propósito em conjunto aos demais elementos ali existentes.

Em seu livro, o autor divide as correntes de estudos estilísticos de Píndaro em duas, as quais, segundo ele, pecam ambas no que diz respeito à sua crítica.

A primeira corrente identificada por Race, inaugurada por $\mathrm{Mezger}^{2}$ e expandida

\footnotetext{
${ }^{1}$ Cf. Race, W. H. Style and Rhetoric in Pindar's Odes. Atlanta: Scholars Press, 1990, p. 1: “A Análise Estilística, no entanto, é deficiente se não leva em conta as razões para cada traço estilístico (...)”.

${ }^{2}$ Cf. Mezger, F. Pindars Siegeslieder. Leipzig: Teubner, 1880.
} 
por Fennel ${ }^{3}$ e Bury, ${ }^{4}$ tinha como objetivo catalogar a recorrência de uma mesma palavra em determinada posição métrica nos poemas, ainda com a intenção de buscar o maius uinculus dentro dos textos. A presença desses estudos, segundo Race, pode-se sentir também, entre outros, na obra de Norwood, ${ }^{5}$ ainda que esse tenha uma preocupação maior em estudar a função do estilo nas odes do que seus predecessores.

Por sua vez, a segunda corrente de estudos estilísticos de Píndaro teve Dornseiff ${ }^{6}$ como fundador e se preocupava em observar a ocorrência de figuras de linguagem e elementos poéticos tradicionais nas odes, mas também falhava, na opinião de Race, por não estudar a significância desses elementos nos poemas em que se inseriam. $O$ extensivo estudo de $\mathrm{Hummel}^{7}$ a respeito da sintaxe de Píndaro se encaixa nessa corrente.

Race, por outro lado, defende o estudo não só dos traços estilísticos das odes, mas também a razão pela qual estes elementos foram usados, ou seja, com que fim foram empregados para modificar ou intensificar as passagens ou mesmo o texto inteiro em que se encontram. ${ }^{8}$

$\mathrm{O}$ presente artigo se insere, pois, na linha de pesquisa adotada por Race, empenhando-se em estudar os elementos estilísticos das odes a fim de procurar entender como esses foram empregados para constituir e definir seu todo.

Desde modo, seguindo a postulação de Race, um elemento de estilo não se define totalmente por si só, mas em um contexto específico, no qual ele atua, modificando-o de alguma forma. Ao mesmo tempo, os demais elementos no seu entorno também exercem uma influência sobre ele, por vezes redefinindo ou ainda acentuando seu caráter natural, de modo a fundamentar a sua existência e acrescer-lhe valor. A partir disso, no uso e na reutilização das palavras e das estruturas pelas quais essas se organizam, é natural que se observem alterações e variações inesperadas nos mais diversos fenômenos estilísticos.

\footnotetext{
${ }^{3}$ Cf. Fennel, C. Pindar's Olympian and Pythian Odes. Cambridge: University Press, 1879.

${ }^{4}$ Cf. Bury, J. The Nemean and Isthmian Odes of Pindar. New York: Harvard University Press, 1892.

${ }^{5}$ Cf. Norwood, G. Pindar. Berkeley/ Los Angeles: University of California Press, 1974.

${ }^{6}$ Cf. Dornseiff, F. Pindars Stil. Berlin: Weidmannsche Buchhandlung, 1921.

${ }^{7}$ Cf. Hummel, P. La Syntaxe de Pindare. Paris: Éditions Peeters, 1993.

${ }^{8}$ Por exemplo, Race (cf. op. cit., p. 41) defende a existência, nas odes de Píndaro, de dois marcadores que teriam o papel de sinalizar o final de uma seção no poema e de preparar o leitor para a aparente mudança abrupta no direcionamento do texto: i) palavras ligadas aos conceitos de morte, derrota e sofrimento, cuja ocorrência na frase a que se ligam é enfaticamente adiada; ii) epifanias e ações divinas. Desse modo, o autor não apenas identifica elementos estilísticos, mas investiga a razão de esses terem sido empregados.
} 


\section{nuntius antiquus}

Sabemos, muitas vezes de forma inconsciente, que há algo incomum em uma passagem de um poema, especialmente naqueles que nos cativam por sua musicalidade. Porém, para irmos além dessa impressão inicial e adentrarmos o cerne da sonoridade do texto, será preciso que estejamos abertos a entendê-lo como um objeto único, cujas características podem ser de uma sutileza inesperada.

Tomemos, por exemplo, o fenômeno estilístico a que se refere comumente por aliteração. Pela gramática tradicional, ele se descreve como o encadeamento sistemático de um mesmo som, geralmente consonantal, ${ }^{9}$ no início de palavras próximas ou, no caso de línguas com acento tônico, em suas sílabas tônicas, ${ }^{10}$ como se pode ver no exemplo abaixo: ${ }^{11}$

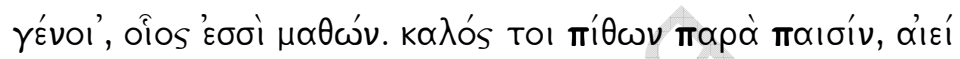

O caso apresentado é bastante modelar em seu uso do som de /p/ no início de três palavras diretamente consecutivas. No contexto em questão, o poeta se prepara para finalizar o poema, despedindo-se de Hierão, o vencedor para quem a ode foi feita, e pedindo-lhe que se torne tal qual é, tendo descoberto o que isto seja - em outras palavras, para que conheça a si mesmo e, tendo entendido o todo de seu ser, para que ele seja fiel àquilo que ele é, sendo ele mesmo e não mais nem menos que isso. Em seguida, para discursar a respeito das coisas verdadeiras e que vão além da aparência e dos enganos, ele afirma, no verso citado acima, que um "macaco" ( mí$\left.^{\prime} \theta \nu\right)$ é "sempre belo"

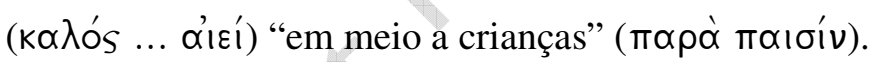

Nessa passagem, contudo, Píndaro se abstém de explicar o significado do lugarcomum que visita com as palavras do verso e, em vez disso, profere a máxima de forma grandiosa, deixando subentendida a intenção da imagem que apresenta. ${ }^{12} \mathrm{~A}$ força

9 O termo "aliteração" é aqui empregado exclusivamente para sons consonantais, assim como "assonância" tem seu uso reservado tão-somente para fazer referência a sons vocálicos.

${ }^{10} \mathrm{O}$ grego antigo, assim como o latim, não se encaixa nesse caso, uma vez que, nele, as sílabas não se diferenciavam por acentos tônicos, mas pelo tempo que se levava para pronunciá-las, de modo a definirem-se como longas ou breves, em vez de tônicas ou átonas. Acredita-se também que o grego possuía, além disso, um acento tonal, como o chinês. Contudo, seu exato funcionamento na fala e, principalmente, na poesia ainda é bastante obscuro para os estudiosos da área.

${ }^{11}$ Cf. Píndaro, Pítica II, 72.

12 Ao que parece, a ideia da máxima é a de que beauty is in the eye of the beholder ("a beleza está nos olhos de quem a vê"). Nesse caso, porém, tem-se a impressão de que a ideia foi utilizada com uma conotação pejorativa, mostrando que as crianças não têm discernimento o bastante para dissociar o conceito puro de beleza do aspecto cômico e caricato do macaco, de modo que o creem belo por sentiremse intrigadas por sua aparência engraçada. 


\section{nuntius antiquus}

aliterativa do verso, nessa conjuntura, é usada para dar consistência à ideia apresentada, agindo de forma a chamar atenção para a imagem e conferindo-lhe peso bastante para entregar a mensagem pretendida sem que fosse necessário ao poeta incorrer em explicações mais pormenorizadas. Assim, em vez de explicar o símbolo a fim de que seu significado ficasse claro, o poeta preferiu investir em sua potência comunicativa, reforçando o significante até um ponto em que sua presença e seu significado não passassem despercebidos pelos seus ouvintes.

Como dito, então, o caso apresentado acima é uma ocasião exemplar de uso de aliteração em /p/ tal qual descreve a gramática. O que se percebeu, no entanto, durante um estudo das figuras de construção nas Píticas, foi que casos puros e modelares como esse são bastante raros nesses poemas de Píndaro. Todavia, antes de essa raridade de efeitos modelares significar uma falta de interesse do poeta em relação ao uso de efeitos sonoros desse tipo, o que procuraremos demonstrar é que Píndaro procurava relegar essas ocasiões modelares para momentos-chave aos quais desejava conceder maior enfoque do que aos restantes, empregando, nos demais momentos, construções mais sutis e orgânicas.

Como exemplo, vejamos a passagem abaixo, em que há uma intensa repetição do som de /p/, ainda que não de forma tão modelar como foi visto no trecho citado anteriormente: ${ }^{13}$

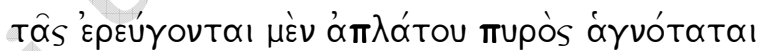

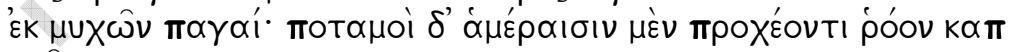
ขoû

Nos versos em questão, a sonoridade marcante em /p/ acentua o aspecto majestoso e explosivo da cena que se descreve; cena na qual "as mais sacras"

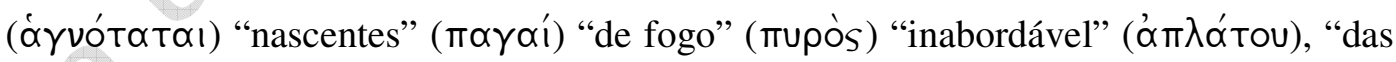

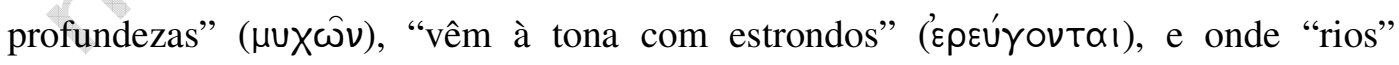
( тот $\alpha \mu \mathrm{\prime})$ que "brilham como fogo" ( $\alpha$ ” $\theta \omega \nu$ no verso seguinte aos citados) "espalham"

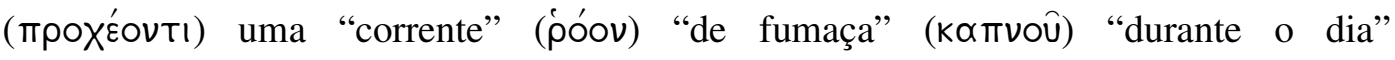

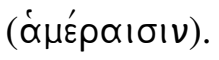

No exemplo, esse artifício sonoro é ainda complementado pelo emprego

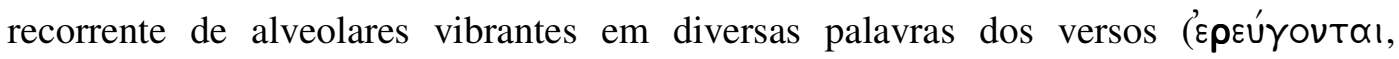

${ }^{13}$ Cf. Píndaro, Pítica I, 21-22. 


\section{nuntius antiquus}

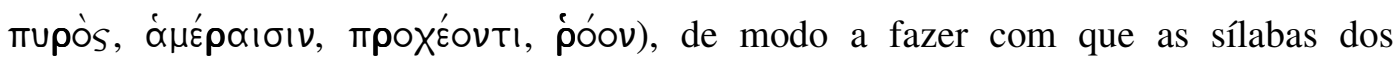
vocábulos rolem da língua para fora da boca de forma viva, borbulhante, sonora, numa qualidade semelhante à da lava ao deixar as profundezas de Etna na imagem descrita pelos versos.

Casos como esse que acabamos de ver, de sequências aliterativas de sons consonantais em posições mistas, são extremamente comuns nas Píticas, ao ponto de quase todo verso possuir ao menos uma aliteração, ainda que fraca, de linguodentais oclusivas, velares oclusivas ou plosivas.

Algumas vezes, aliás, durante o estudo desses aspectos estilísticos das Píticas, notou-se o emprego de aliterações para efeitos bastante sutis e contundentes, como se pode ver a seguir: ${ }^{14}$

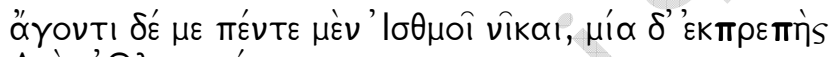

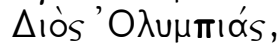

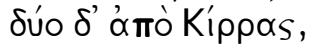

No caso apresentado, os versos apresentam um modo de construção recorrente nas Píticas, no qual Píndaro aproveita algum som vocálico ou consonantal de um nome próprio para criar uma aliteração ou assonância de força variável. Ali, o nome

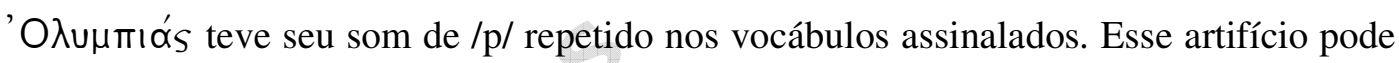
ser observado em várias das odes, principalmente em relação ao nome do vencedor em honra ao qual o poema foi composto. Nessas circunstâncias, a aliteração ou assonância costuma ser ainda mais notável do que nas demais.

Vejamos, então, alguns outros exemplos de aliterações criadas a partir de nomes próprios: ${ }^{15}$

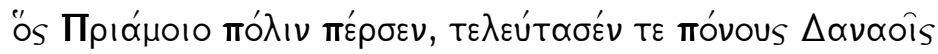

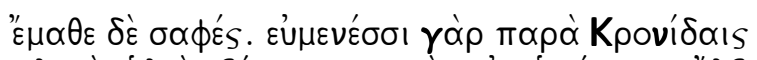

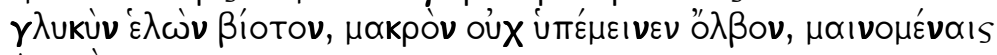
$\phi \rho \alpha \sigma i v$

\footnotetext{
${ }^{14}$ Cf. Píndaro, Pítica II, 13-16.

${ }^{15}$ Cf. Píndaro, Pítica I, 54/ Pítica II, 25-26.
} 


\section{nuntius antiquus}

No primeiro desses novos exemplos, vê-se como o nome de "Príamo"

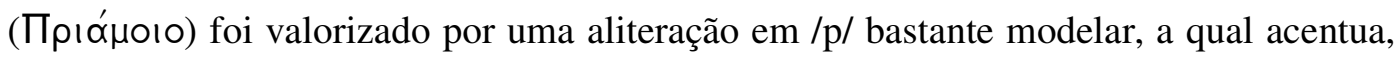
principalmente, o aspecto destrutivo da ideia à qual o verso remete (de Troia sendo destruída). Em seguida, no segundo exemplo, pode-se notar a forma pela qual a

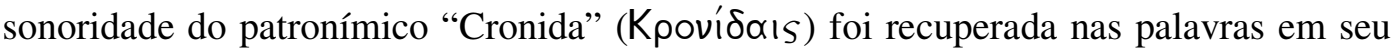
entorno, bem como ao longo do verso seguinte inteiro, retomando não só o som de /k/ em algumas velares oclusivas, mas também o de /n/ em todos os vocábulos que sucedem a aparição do nome próprio.

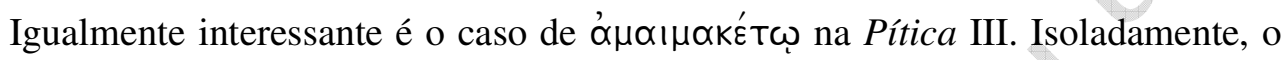
vocábulo já é bastante forte em termos sonoros, por repetir o som de $/ \mathrm{m} /$, que, nas Píticas, não é muito comum, especialmente quando comparado à frequência com a qual se notam sons oclusivos, por exemplo. Como se pode ver abaixo, no entanto, em adição à força do vocábulo, mencionada anteriomente, havia outras ocorrências do mesmo som

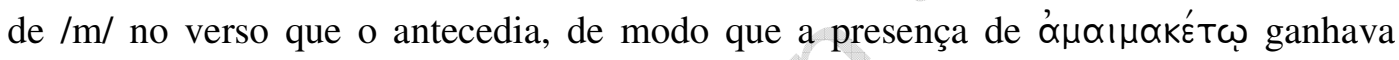
ainda mais força no contexto em que se encontrava: ${ }^{16}$

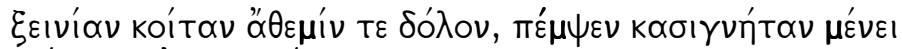

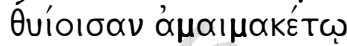

No contexto da passagem, o poeta descreve a cena em que Korônis, grávida de Apolo, trai sua confiança ao dormir com o estrangeiro Ísquis. No caso examinado, o

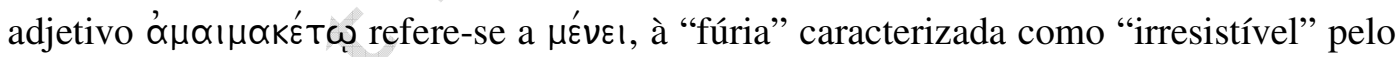
vocábulo em questão, fúria essa com a qual o deus enviou sua irmã, Ártemis, para a

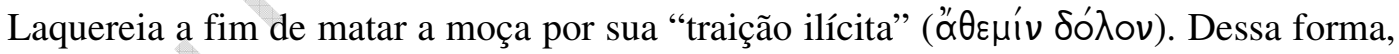
soube o poeta dar um destaque enfático à inevitabilidade destrutiva da fúria divina, tanto pela sonoridade isolada do adjetivo que a qualifica quanto pelo crescendo sonoro que ali foi empregado para introduzi-lo.

Assim, ao que nos parece, por meio da amostragem controlada do som de $/ \mathrm{m} /$, Píndaro pretendia fazer com que seus ouvintes estivessem mais inclinados a receber e

\footnotetext{
${ }^{16}$ Cf. Píndaro, Pítica III, 32-33.
} 


\section{nuntius antiquus}

perceber a retomada deste mesmo som num momento de maior importância, assimilando, então, a ênfase dramática e o maior destaque concedido ao vocábulo. ${ }^{17}$

Outra particularidade que se notou, em relação a aliterações, foi a do uso frequente de sons consonantais de um mesmo ponto de articulação como um único grupo. Dessa forma, não se consideram como aliterações apenas, por exemplo, sequências puras de /p/, /ph/ e /b/, mas sim de plosivas em termos gerais, tal qual se pode notar nos versos que se seguem àqueles apresentados no segundo exemplo deste capítulo, onde também havia uma aliteração de plosivas bastante forte: ${ }^{18}$

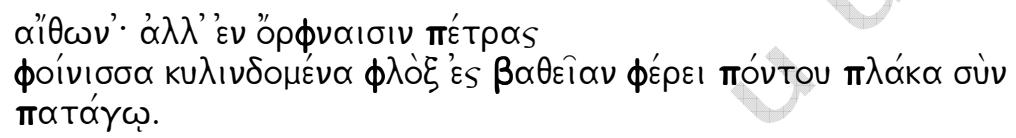

No caso supra-examinado, pode-se perceber que os sons de /ph/ e /b/ fazem parte integrante da longa sequência de plosivas empregada por Píndaro, complementando o som primário de /p/ e harmonizando-se com ele de forma quase que indistinta. $\mathrm{O}$ resultado sonoro desse artifício é, de certa forma, semelhante ao resultante de toques de diferente intensidade sobre uma mesma tecla de piano, os quais, com efeito, podem produzir sensações distintas, mas que, nem por isso, deixam de ser variações da mesma textura sonora.

Por toda a extensão das Píticas, Píndaro faz um uso aparentemente indiscriminado das mais diversas combinações de sons semelhantes. Mais adiante neste artigo, procuraremos mostrar como essa característica do estilo do poeta se apresenta como um dos alicerces principais de seu método de composição. Antes, contudo, é preciso salientar que esse uso de aliterações é indiscriminado somente no tocante à mistura dos diferentes sons de um mesmo tipo, mas não quanto à ocorrência de aliterações puras, sem variação entre fonemas de uma mesma categoria sonora. De fato, quando se encontra uma cadeia limpa de sons de /p/, por exemplo, há uma grande chance de haver uma ênfase incomum ao contexto da passagem. Por outro lado, a mistura de /p/ e /b/ ou de /p/ e /ph/ não parece ser um critério de diferenciação em termos de ênfase estilística.

\footnotetext{
${ }^{17}$ Alguns outros exemplos em que se pode notar um efeito de amostragem semelhante são: Pítica III, 1315; Pítica III, 40; Pítica III, 61.

${ }^{18}$ Cf. Píndaro, Pítica I, 23-24.
} 


\section{nuntius antiquus}

Essa característica que se nota nas Píticas de um emprego de aliterações mais sutis e orgânicas se nos passou, de fato, quase que inteiramente despercebida num momento anterior, quando realizamos uma análise e tradução da Pítica VIII no mestrado. ${ }^{19}$ Naquela ocasião, havíamos notado que os versos da ode eram, em sua grande maioria, muito bem trabalhados e bastante eufônicos, por conta de uma notável escassez de efeitos que se sobressaíssem em demasia dos restantes. Essa constatação não estava de todo equivocada, mas carecia de uma fundamentação maior, a qual agora acreditamos poder fornecer.

O que se percebeu, enfim, é que esse uso de aliterações mais abrandadas parece evidenciar uma técnica estilística de Píndaro, cuja função apontaria para a manutenção da eufonia ao longo de seus poemas. Segundo essa hipótese, que acreditamos ser passível de formulação com base nos indícios levantados, o poeta empregaria consoantes velares e linguodentais oclusivas, bem como plosivas, como tecido sonoro primário de seus versos. Assim, da mesma forma pela qual o músico erudito combina e modula escalas, ora alternando entre as notas de um mesmo conjunto melódico, ora permitindo-se empréstimos modais a fim de realçar a harmonia predominante por meio da inclusão de uma sonoridade distinta, Píndaro solidifica a tessitura sonora fundamental de seus poemas pela combinação desses três grupos de sons.

$$
\text { Exemplos: }{ }^{20}
$$

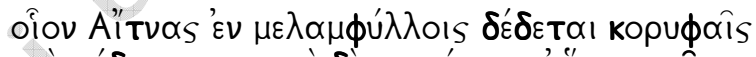

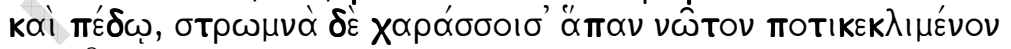
KЕVTยิ.

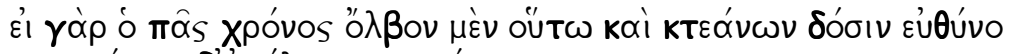

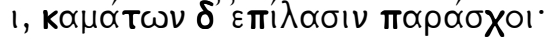

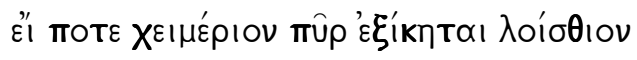

Esses são apenas alguns exemplos, cujos artifícios estilísticos criam uma sonoridade mais concentrada e nos quais se pode perceber uma ampla ocorrência de

\footnotetext{
${ }^{19}$ Cf. Antunes, C. L. B. Ritmo e sonoridade na poesia grega antiga. Uma tradução comentada de 23 poemas. Dissertação de mestrado inédita. São Paulo: DLCV/ FFLCH-USP, 2009, p. 129-132.

${ }^{20}$ Cf. Píndaro, Pítica I, 27-28/ Pítica I, 46/ Pítica IV, 266.
} 


\section{nuntius antiquus}

consoantes velares e linguodentais oclusivas e de plosivas.

Nota-se ainda, nessas passagens, a maneira pela qual, quando lidas em voz alta, as consoantes destacadas parecem encadear o ritmo dos versos, conduzindo-os como a força primária neles atuante. De velar para linguodental ou plosiva, ou pela repetição de um único grupo consonantal, variando ou não o fonema entre aqueles possíveis no mesmo conjunto, essas três categorias de consoantes são a matéria básica da estruturação sonora das Píticas, marcando seu tom e ritmo. Os demais grupos de consoantes, por sua vez, encaixam-se como uma substância mais sutil, mais fina, que se amalgama entre as ranhuras que separam os grupos primários, conferindo-lhes consistência, uniformidade e harmonia, ao passo que as vogais ali presentes definem, por fim, a melodia do conjunto, atuando na matização dos versos e alterando-os em sua camada mais exterior e de maior delicadeza.

No primeiro verso da primeira das passagens citadas, por exemplo, vê-se como o poeta, para estruturar o andamento do ritmo, alterna, mormente, entre as linguodentais oclusivas /t/ e /d/ e a plosiva /ph/, havendo ainda uma ocorrência isolada do som de /k/, que prepara o campo sonoro para a mudança que haverá no verso seguinte, onde as velares oclusivas $/ \mathrm{k} / \mathrm{e} / \mathrm{kh} /$ serão mais exploradas, persistindo ainda as ocorrências de linguodentais oclusivas e tendo o verso sua representante plosiva em /p/.

Esse primeiro verso tem uma sonoridade bastante suave, criada, em parte, pela abundância de sons de $/ \mathrm{m} /, \mathrm{n} /$ e $/ 1 /$, os quais complementam os três grupos básicos de sons consonantais mencionados. Essa suavidade, ademais, é salientada por uma variação vocálica bastante controlada, que cria uma melodia bem definida (repetindo-se, de forma monótona, os sons de /a/, /e/, /o/ e /u/) e abrandada pelas homofonias em /i/ advinda dos vários ditongos presentes.

O verso seguinte, por sua vez, tem sons consonantais secundários mais marcantes, com especial enfoque na alveolar vibrante /r/, cuja presença, assim como se deu com $/ \mathrm{k} /$, foi antecipada em kopuфaîs, o vocábulo final do primeiro verso. A ausência da homofonia em /i/ vista nos ditongos do verso anterior, além de uma presença acentuada do som de /ó/, atua de modo a aumentar a complexidade melódica desse verso, diminuindo, portanto, sua monotonia. Esse efeito se faz ainda mais marcante pela variedade de sons consonantais usados para conferir um encadeamento mais orgânico e pleno de verve ao verso.

Nesses dois versos, o poeta descreve o relevo da região de Etna. No primeiro, 


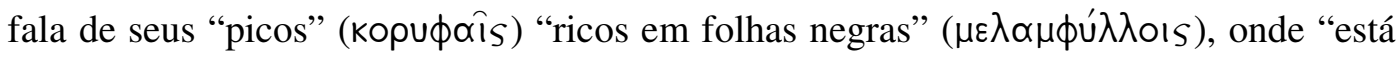
preso" ( $\delta \varepsilon \delta \varepsilon \tau \propto \triangleleft)$ Tífon. A sonoridade mais branda, portanto, é congruente com o tema soturno, marcado, no campo semântico, pelo aspecto negro das folhas encontradas nos picos de Etna e pela própria ideia do aprisionamento da criatura. Por outro lado, o segundo verso já descreve um terreno mais plano, porém acidentado, o qual, apesar de

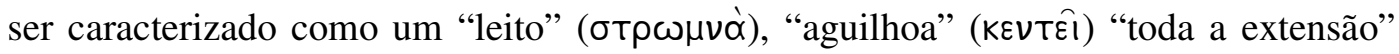

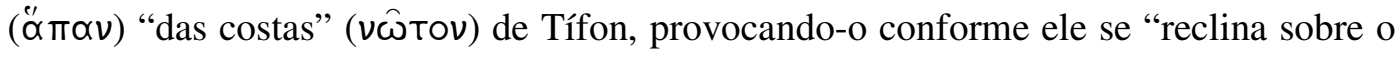
local" ( $\chi \propto \rho \alpha ́ \sigma \sigma o ı \sigma)$. Por incitar o monstro dessa forma é que o mito explica a lava jorrar do vulcão de Etna, vinda das profundezas da terra e do próprio Tífon. Dessa forma, o ritmo acompanha a mudança de humor do plano semântico, fazendo-se mais variado e acentuado, quase tão agudo e acidentado quanto o terreno que nele se descreve.

O segundo exemplo, por sua vez, se nos apresenta como um verso bastante longo e que traz, em si, uma frase completa na forma de uma volição. Nele, o poeta

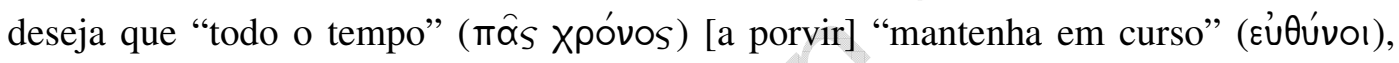

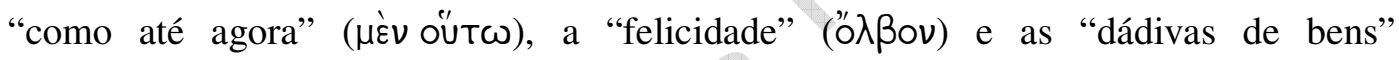

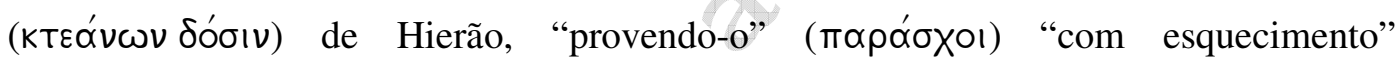

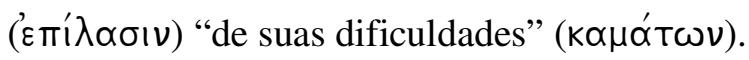

A estrutura sonora básica do verso foi criada com impressionante cuidado, inicialmente variando entre velares oclusivas e plosivas, depois entre linguodentais e velares oclusivas, e finalmente retornando para a variação inicial de velares oclusivas e plosivas e terminando o verso, como se pode ver na divisão abaixo: ${ }^{21}$

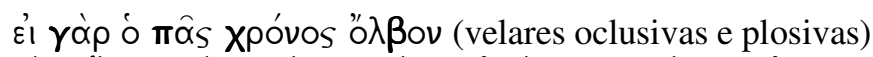

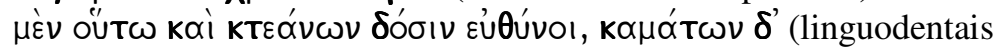
e velares oclusivas)

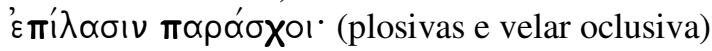

É igualmente notável observar como os dois grupos de sons consonantais secundários de maior peso empregados na primeira divisão (a saber, as alveolares vibrantes e líquidas) também se repetem na terceira, mas encontram-se de todo ausentes na seção intermediária da passagem, reforçando a estrutura anelar que se cria em seu plano sonoro. As alveolares fricativas, de modo semelhante, têm duas ocorrências tanto

${ }^{21}$ Cf. Píndaro, Pítica I, 46. 
na primeira quanto na terceira seção do verso, porém apenas uma na seção medial. Finalmente, quanto a sons vocálicos, a região central do verso possui uma variação marcante, destacando-se o som de /ó/, ao passo que as duas outras seções são marcadas mormente por sons de /a/, /o/ e /i/, esse último mais presente na terceira divisão do verso.

Toda essa riqueza de detalhes sonoros funciona, em relação ao plano semântico, como um reforço para a completude da ideia exposta, dando ao verso ainda maior autonomia de sentido pela criação de uma estrutura anelar em seu interior. Essa composição anelar atua de forma sutil, colaborando para que se tenha uma sensação de começo, meio e fim, advinda de uma ordenação aparentemente lógica, na qual a ideia inicial seria retomada no final da passagem. Contudo, quando se analisa o conteúdo semântico do verso, o que se vê é que esse padrão anelar se limita apenas ao plano estrutural, de modo que a sonoridade funciona, no verso, como um recurso retórico para dar maior credibilidade às ideias ali expostas.

Finalmente, o terceiro exemplo citado, ao contrário do anterior, é um verso de tamanho reduzido. Apesar de sua extensão limitada, ele apresenta uma construção bastante peculiar, na qual os três grupos primários de sons consonantais são utilizados alternadamente. De fato, logo nos três primeiros vocábulos do verso, o poeta já emprega um elemento de cada grupo consonantal primário, começando pela plosiva /p/, passando para a linguodental oclusiva / $\mathrm{t} / \mathrm{e}$, finalmente, completando o ciclo com a velar oclusiva $/ \mathrm{kh} /$. Em seguida, dá-se início a um novo ciclo, novamente com /p/, a que se seguem duas velares oclusivas antes de a estrutura básica se concluir com mais dois sons de linguodentais oclusivas.

$\mathrm{Na}$ segunda camada de sons consonantais, há uma presença marcante de alveolares vibrantes, complementadas por uma alveolar líquida no final do verso. A presença de um som de $/ \mathrm{m} /$ no início do verso, ao lado de duas ocorrências de $/ \mathrm{n} / \mathrm{e}$ de três ditongos com /i/, colabora para que a sonoridade seja bastante suave. A escassez de vogais abertas, igualmente, faz com que o tom do verso seja brando e controlado.

Por fim, no campo semântico, o verso faz parte de uma passagem na qual o poeta fala da sabedoria de Édipo, dizendo que, ainda que alguém corte os galhos de um grande carvalho e arruíne sua aparência esplêndida, ele ainda dá um testemunho de si

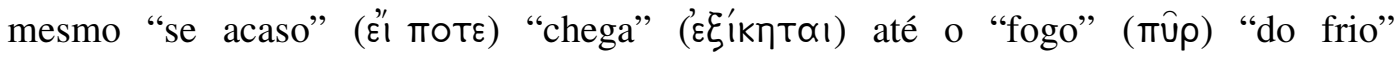

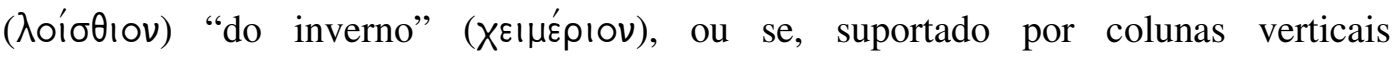




\section{nuntius antiquus}

pertencentes a um mestre, executa um trabalho infortunado em paredes alheias, tendo deixado seu próprio lugar desolado.

A ideia que à passagem convém, portanto, é de que, ainda que as coisas mudem, elas têm seu próprio lugar e função no mundo. Nesse contexto, a organização extrema do verso vem a corroborar essa noção de que há ordem mesmo no aparente caos de eventos fortuitos.

Não é de se estranhar, realmente, que Píndaro demonstre, nas Píticas, uma predileção por esses fonemas mais sóbrios, uma vez que a ocasião de performance desses poemas requeria, com efeito, uma tonalidade mais austera, porém grandíloqua, devido à constante eufonia alcançada, em boa parte, por meio dos artifícios citados.

A opção por uma frequência maior de efeitos sutis também é congruente com o comedimento altivo que certamente era esperado de uma ode de vitória, uma vez que um uso mais frequente de aliterações pesadas e efeitos menos sutis poderia acabar por conceder emoções muito variadas e excessivas às odes.

Assim, esperamos ter conseguido apresentar algumas das maneiras por meio das quais Píndaro estruturou a sonoridade das Píticas num contínuo jogo com o sentido e os demais elementos formais do texto. Nessa conjuntura, as características do estilo se apresentam como matéria própria e inerente ao texto, de modo não só a modificá-lo ou acentuá-lo, mas também a justificar sua própria existência enquanto artifícios de composição, de modo que tanto o texto não se sustenta plenamente sem o estilo a ele adaptado, quanto o estilo não se valida fora de uma circunstância semelhante àquela para a qual ele se desenvolveu.

\section{Referências}

ANTUNES, C. L. B. Ritmo e sonoridade na poesia grega antiga. Uma tradução comentada de 23 poemas. Dissertação de mestrado inédita. São Paulo: DLCV/ FFLCHUSP, 2009.

BURY, J. The Nemean and Isthmian Odes of Pindar. New York: Harvard University Press, 1892.

DORNSEIFF, F. Pindars Stil. Berlin: Weidmannsche Buchhandlung, 1921. 


\section{nuntius antiquus}

FENNEL, C. Pindar's Olympian and Pythian Odes. Cambridge: University Press, 1879.

HUMMEL, P. La Syntaxe de Pindare. Paris: Éditions Peeters, 1993.

MEZGER, F. Pindars Siegeslieder. Leipzig: Teubner,1880.

NORWOOD, G. Pindar. Berkeley/ Los Angeles: University of California Press, 1974.

RACE, W. H. Pindar: Olympian Odes, Pythian Odes. Cambridge, Mass./ London: Harvard University Press, 1997. . Style and Rhetoric in Pindar's Odes. Atlanta: Scholars Press, 1990.

WEST, M. L. Introduction to Greek metre. Oxford: Clarendon Press, 1987. 